\title{
O GÊNERO PROVA OBJETIVA NO SUPORTE DIGITAL: UMA ANÁLISE DA PERCEPÇÃO DOS ALUNOS DO CURSO DE LETRAS ${ }^{1}$
}

Cristiane Magalhães (UEG)

Carla Conti de Freitas (UEG)

Resumo: O gênero prova objetiva foi objeto de uma pesquisa que busca analisar a percepção dos alunos do curso de Letras acerca do suporte digital para o gênero prova objetiva, além de verificar se esse suporte interfere na definição e na compreensão desse gênero. A abordagem dada ao tema baseia-se nos estudos da análise de gêneros textuais, especialmente nas contribuições teóricas de Marcuschi (2002; 2008), Bezerra $(2007 ; 2017)$ e outros. Para realização da pesquisa, foi considerada uma turma do 4 ํ período do curso de Licenciatura em Letras, de uma universidade pública, na disciplina de Diversidade, Cidadania e Direitos. O gênero escolhido foi a prova objetiva, elaborada a partir do conteúdo ministrado no período da pesquisa e o suporte foi uma plataforma digital, denominada Plickers. $O$ córpus foi constituído pelos relatos produzidos pelos alunos depois da realização da prova. $\mathrm{Na}$ análise dos relatos, considerou-se a percepção dos alunos quanto ao gênero prova objetiva e a interferência do suporte digital na compreensão do referido gênero. Como resultado deste estudo, compreende-se que a percepção dos alunos quanto ao gênero e a contribuição do suporte digital para este gênero é importante para a aproximação dos alunos aos contextos que exigem conhecimento e habilidade com este gênero, como os relacionados às disciplinas semipresenciais, aos concursos e aos exames de avaliação de curso.

Palavras-chave: Gênero textual; Prova objetiva; Suporte; Plickers.

Abstract: The gender objective test was the object of a research that seeks to analyze the students' perception of the Language course about the digital support of the gender objective test, besides verifying if this support interferes in the definition and the comprehension of this genre. The approach given to the theme is based on the studies of the analysis of textual genres, especially in the theoretical

1 Título em língua estrangeira: "The gender objective test in a digital support: an analisys of students' perception in the language course" 
contributions of Marcuschi (2002; 2008), Bezerra (2007) and others. For the accomplishment of the research, it was considered a group of the 4th period of the degree course in Letters, of a public university, in the discipline of Diversity, Citizenship and Rights. The chosen genre was the objective proof, elaborated from the content taught during the period of the research and the support was a digital platform, called Plickers. The corpus was constituted by the reports produced by the students after the test and the analysis of the reports considered the students' perception regarding the gender objective test and the interference of the digital support in the understanding of the said genre. As a result of this study, we understand that the students 'perception of the genre and the contribution of digital support to this genre is important for the students' approach to the contexts that demand knowledge and skill with this genre, such as those related to semipresencial subjects, and course evaluation exams.

Keywords: Textual genre; Objective test; Support; Plickers.

\section{INTRODUÇÃO}

Neste artigo, apresentamos uma discussão sobre a percepção de futuros professores sobre o gênero prova objetiva no suporte digital. A proposta é analisar a percepção dos alunos acerca do suporte digital para a prova objetiva e verificar se esse suporte interfere na definição e compreensão do gênero.

Para este estudo, é importante destacar a diferença entre gêneros discursivos e gêneros textuais, pois, para a escolha do gênero prova objetiva, é necessário o conhecimento, a história e suas aplicações em atividades discursivas bem como sua relevância na análise do discurso e análise textual para verificar sua funcionalidade no suporte tecnológico e na apresentação do gênero escolhido. De acordo com Rojo (2005, p.185), 
a teoria de gêneros do discurso ou discursivos e de gêneros textuais, [...] encontravamse enraizadas em diferentes releituras da herança bakhtiniana, sendo que a primeira - teoria dos gêneros do discurso - centravase sobretudo no estudo das situações de produção dos enunciados ou textos e em seus aspectos sócio-históricos e a segundateoria dos gêneros de textos -, na descrição da materialidade textual.

A diferenciação entre gêneros discursivos ou textuais para indicar uma maior ou menor aproximação com a perspectiva bahktiniana e outras perspectivas, que buscam uma distinção entre gêneros e tipos, possibilita refletir sobre o funcionamento de gêneros discursivos e textuais. Alguns estudos buscam justificar a questão da escolha gênero prova, notando assim as aproximações e diferenças defendidas por eles em diferentes enfoques que podem resultar em maior ou menor proveito quando de sua aplicação, especialmente, no ensino de línguas. (BEZERRA, 2017).

Este tema surgiu da reflexão acerca das experiências observadas nos cursos de formação de professores, considerando os modelos de provas aplicados durante 0 curso, em oposição aos modelos de exames que os alunos são submetidos a o final do curso como o ENADE e após concluírem a graduação como os concursos ou as especializações feitas na modalidade de educação a distância, doravante EAD. 
Pensando em possibilitar novas práticas, embasadas na teoria dos multiletramentos, decidimos aplicar uma prova objetiva para uma turma de 4o período do curso de Letras, na disciplina de núcleo comum "Diversidade, Cidadania e Direitos", utilizando como instrumento uma plataforma digital denominada Plickers.

Para isso, iniciamos este artigo, que está organizado em quatro momentos, apresentando uma breve discussão do referencial teórico, considerando as contribuições teóricas de Marcuschi (2002; 2008), Bezerra (2007; 2017) e Rojo (2005) para os estudos da análise de gêneros textuais e suporte de gêneros e de Araújo (2007) com reflexões acerca do texto e do discurso por diversos olhares. Em seguida, abordamos os aspectos metodológicos, inspiradas pela abordagem hermenêutica fenomenológica complexa, proposta por Maximina Freire (2017). Na sequência, apresentamos a análise das informações obtidas por meio das respostas a duas perguntas ao final da aplicação da prova e, por fim, as considerações finais, retomando os objetivos da proposta e os respectivos resultados.

\section{DISCUSSÃO TEÓRICA}

Este tópico será importante para entender a noção de língua (BAKHTIN, 2006) pela qual os indivíduos estabelecem 
relações sociais, que se dão por meio da interação verbal. Importante, também, para compreender os conceitos de gêneros e seu suporte, em especial, os gêneros textuais.

\subsection{Os gêneros textuais}

O estudo dos gêneros é bem mais antigo do que pensamos. Desde muitos anos, já se considerava sua observação sistemática (MARCUSCHI, 2008). Em nosso dia-a-dia, nos deparamos com os mais variados tipos de leituras e estamos envolvidos nas mais diversas situações de comunicação. Fazemos uso de diferentes formas de interação, oral, escrita, e/ou gestual que, dependendo da cada circunstância, pode ser alterada a qualquer momento, pois a linguagem é peça chave para a comunicação, passível de ação e adaptação. De acordo com Bakhtin (2006, p.127), a língua é o meio pelo qual os indivíduos estabelecem as interações e relações sociais:

A verdadeira substância da língua não é constituída por um sistema abstrato de formas linguísticas nem pela enunciação monológica isolada, nem pelo ato psicofisiológico de sua produção, mas pelo fenômeno social da interação verbal, realizada através da enunciação ou das enunciações. A interação verbal constitui assim a realidade fundamental da língua. (BAKHTIN 2006, p.125)

E é justamente nessas relações de interação verbal e social que surgem os gêneros. Nas contribuições de Marcuschi (2002, p.19), vimos que, 
já se tornou trivial a ideia de que os gêneros textuais são fenômenos históricos, profundamente vinculados à vida cultural e social. Fruto de trabalho coletivo, os gêneros contribuem para ordenar e estabilizar as atividades comunicativas do dia-a-dia. São entidades sócio-discursivas e formas de ação social incontornáveis em qualquer situação comunicativa.

Nesse sentido, percebemos que ao longo da história e a partir da necessidade de nos comunicarmos, surgem os gêneros textuais, os quais estão relacionados à estrutura, forma e funcionalidade (BAKHTIN, 2011). Para Bakhtin (2011) "cada enunciado particular é individual, mas cada campo de utilização da língua elabora seus tipos relativamente estáveis de enunciados, os quais denominamos gêneros do discurso" (p.262, grifos do autor). Assim, os gêneros são incontáveis e a cada situação é possível que um novo seja criado, ou seja, os gêneros estão relacionados ao tipo de conteúdo veiculado, mas também possuem modelos predefinidos.

Para Bakhtin (2006), a língua é vista como meio de interação social, ou seja, ela não é usada somente para comunicação, mas também para concretizar ações por meio da interação social e cognitiva dos falantes, levando em consideração às situações de interlocução nas quais a língua se realiza e há a influência de fatores externos aos aspectos puramente linguísticos. 
Os gêneros textuais são enunciados, formas verbais de ação social relativamente estáveis, que se apoiam em tipos textuais, situados em comunidades de práticas sociais e em domínios discursivos específicos (MARCUSCHI, 2002), ou seja, surgem principalmente, em virtude da dinâmica das interações sociais.

A capacidade de movimento e a dinamicidade da linguagem e da comunicação permitem que os gêneros sofram modificações no decorrer do tempo, ou seja, novos gêneros surgem a partir de outros já existentes. É o caso das cartas, que antes eram escritas e enviadas via correios e que, com as inovações tecnológicas, tal gênero tem sido substituído pelo e-mail, embora mantenha traços comuns com o gênero inicial. Os gêneros textuais apresentam sua função social de acordo com as situações comunicativas, por isso, estão intrinsecamente ligados à história da comunicação e da linguagem.

No campo do ensino, é possível perceber que a pluralidade das linguagens e aprendizagens gera diferentes leituras que, pelo seu potencial de comunicação, constitui um fascinante campo de estudo, ao qual se juntam novas possibilidades e tecnologias que, sinalizam e ampliam o debate e o questionamento acerca do uso de gêneros 
textuais com suportes tecnológicos para ressaltar a abrangência a natureza deste estudo, no qual a língua e as linguagens evoluem e operam em estratégias e formas desenvolvidas, permitindo, portanto, o desenvolvimento em novas estruturas para interação e intervenção em contextos possíveis para formação de professores e participação no processo de ensino.

Os gêneros discursivos textuais divergem e convergem, em competências e consequências, decorrentes do uso da língua e das práticas pedagógicas, tecendo considerações entre gênero textual e discursivo. Na linguística, Bakhtin (2011) é considerado referência teórica sobre gêneros discursivos/textuais, destacando a língua como forma de ação social, histórica e específica em dada situação sócio comunicativa que se realiza em forma de enunciados (orais e escritos), determinado em forma e tipos para as diversas situações interlocutivas, refletindo condições e finalidades em atividades sócio discursiva e tecnológica a que se vincula. Para compreender gênero em ação social, metodológica e aplicação, diversos teóricos pesquisadores buscam diminuir a distância entre os mundos clássicos e modernos, argumentando estratégias com objetivo de persuadir incorporar e atingir determinado propósito em certas situações social e linguística. 
Na sequência, abordamos as questões do suporte para os gêneros textuais.

\subsection{O suporte para os gêneros textuais}

Muito se discute a respeito do suporte dos gêneros textuais, no entanto, devido à falta de estudos sistemáticos a respeito do suporte de gêneros textuais, acaba-se por cometer equívocos ao procurar uma definição para tal ou ao tentar identificá-lo.

Para Marcuschi (2008), há sempre uma estreita relação entre gêneros e seus suportes: o conteúdo não irá mudar, porém o gênero será sempre identificado a partir do suporte que está sendo veiculado. Nesse sentido, o autor define suporte da seguinte maneira,

entendemos aqui como suporte de um gênero um locus físico ou virtual com formato específico que serve de base ou ambiente de fixação do gênero materializado como texto." Pode-se dizer que suporte de um gênero é uma superfície física em formato específico que suporta, fixa e mostra um texto. (MARCUSCHI, 2008, p.174)

Para que o gênero circule na sociedade é imprescindível que haja o suporte, não sendo necessário que o suporte determine o gênero, ou influencie em sua natureza, mas que o gênero exija um suporte específico, sendo que em 
algum momento pode ou não determinar a natureza do gênero, numa relação de fatores combinados no contexto emergente. Então, chega-se a definição de que suporte não é neutro, é um locus físico ou virtual com formato específico e serve de base para que o gênero seja materializado, em texto, forma ou imagem.

A escolha de diferentes teorias e suas finalidades voltadas para o ensino defende a eficácia social e se coloca de maneira virtual para desenvolver uma análise de prática e procedimento explorando competências linguísticas, situações comunicativas, conhecimento e crítica. Nosso foco, para discutir a relação entre gêneros e seus suportes está nas contribuições de Bezerra (2007; 2017).

O autor diz que o suporte é onde o gênero se materializa e pode se modificar não existindo hierarquia entre gênero e suporte, pois ambos precisam existir para a construção de seus significados, que em seu processo histórico atua em diferentes formas, procedimentos e condições de produção que justificam as mudanças ocorridas na forma de teste escrito e na relação intrínseca entre suporte e gênero, que através da evolução da imprensa pode ser visto em diversos tipos de materiais que foram utilizados para o suporte da escrita como: tábuas, pedra, osso, madeira, couro, metal, 
papiro, pergaminho, etc., até a chegada do livro impresso. Em nossos dias, a era dos computadores ou era digital, o suporte digital no caso, é o foco desse estudo e diz respeito às configurações do suporte e as possibilidades de sua aplicação e funcionalidade no desenvolvimento de novos avanços tecnológicos e o surgimento de novos gêneros textuais, tanto na escrita quanto na oralidade e também no âmbito da comunicação digital. Em suas considerações, Bezerra (2007, p.35) ressalta que,

investigações empíricas de diversificada natureza deverão ampliar e também corrigir continuamente nossa percepção teórica atual sobre o lugar dos suportes na constituição, identificação nomeação e uso dos gêneros no interior das mais variadas práticas sociais, ao lado dos aspectos já costumeiramente levados em conta.

Sendo assim, essa nova forma de nos relacionarmos com a escrita e a tecnologia nos permite a organização e o registro do conhecimento, bem como, as várias práticas discursivas em diversos suportes que de maneira criativa promovem a hipertextualidade e criam interações. Nesse sentido, a ressignificação da escrita e o sucesso de suas interlocuções virtuais, em que a língua seja um lugar de interação humana e em situação de igualdade midiática é perceptível às influências do suporte e da função social 
das práticas discursivas nas práticas de comunicação e ressignificação da escrita, percebendo assim a influência do suporte nas práticas associadas a estratégias no meio digital, buscando suprir a ausência do físico-espacial (ARAÚJO, 2007) e desenvolvendo habilidades como: o uso do teclado, do mouse e a digitação. Nas palavras do autor,

Em Bakhtin, a escrita nos gêneros chats, pode ser bem mais compreendida se as idiossincrasias gráficas ali encontradas forem vistas além da sinalidade, isto é, como ressignificação e não como desvio de norma. Nas discussões sobre o suporte, porque a tela digital, como mídia do bate-papo, busca suprir a ausência físico-espacial dos interlocutores, reunindo várias semioses a um só tempo. (ARAÚJO, 2007, p.43)

Tais transformações exigem a desenvoltura de novas competências: a competência para múltiplas escolhas e competência tecnológica, combinando expectativas e buscando compreender o gênero "prova objetiva" com um suporte tecnológico necessário e eficiente na formação de professores, ressignificando suas práticas, inovando e modernizando técnicas e competências na era digital.

A seguir, uma breve apresentação acerca da metodologia escolhida para desenvolver a pesquisa, a abordagem hermenêutica fenomenológica complexa, proposta por Maximina Freire (2017). 


\section{ASPECTOS METODOLÓGICOS}

A escolha metodológica foi a abordagem hermenêutica fenomenológica complexa, proposta por Freire (2017), pois consideramos que este estudo envolve conhecimento e experiências, buscando credibilidade no cenário metodológico, confrontando a pesquisa quantitativa em vertentes qualitativas, em termos de procedimentos, validade e confiabilidade, sinalizando para novos percursos e descobertas.

Da abordagem hermenêutica fenomenológica complexa, são destacados três processos (FREIRE, 2017): textualização, tematização e ciclo de validação que contribuem para a relação entre a pesquisa do suporte para o gênero prova objetiva, levando em consideração a percepção dos envolvidos, o conhecimento e a aceitação da metodologia aplicada, explicando sua relação de aceitação e dificuldades encontradas.

Nesta abordagem, destaca-se o princípio da complexidade que compõe o fenômeno da experiência em si, relacionando processos e investigando unidades menores para a ressignificação desejada, bem como a contribuição para o fenômeno investigado e concluído.

Consideramos como contexto e participantes desta pesquisa, os alunos do 4 o período o curso de Letras - 
Português/Inglês da Universidade Estadual de Goiás, Câmpus Inhumas, matriculados na disciplina "Diversidade, Cidadania e Direitos", no segundo semestre de 2018.

\subsection{O gênero textual prova objetiva}

Este artigo descreve uma avaliação da disciplina "Diversidade, Cidadania e Direitos", por meio de uma prova objetiva, considerada como um gênero. Durante aulas anteriores à da avaliação, os alunos participaram de momentos de discussões acerca de conceitos relacionados à disciplina, tais como cultura, gênero diversidade, direito, cidadania, preconceito, racismo, etc.; fizeram a leitura do livro "Humanidade sem raças" de Sérgio Pena e do conto "O Embondeiro que sonhava pássaros" de Mia Couto; e, ainda, assistiram a um documentário exibido no FuturaPlay, "Making of: Diz aí Afro e indígena". Na sequência, realizaram a prova objetiva sobre conteúdo, como uma das atividades avaliativas da disciplina. Depois, cada participante respondeu um questionário com duas perguntas que se tornou córpus da pesquisa.

\section{2. Plataforma Plickers}

Com base nos estudos sobre gêneros textuais foi escolhida a prova objetiva e, como suporte de gêneros, a plataforma Plickers. Com esta escolha, buscamos compreender como o 
suporte pode transformar ou interferir na compreensão de determinado gênero.

A Plickers é uma ferramenta digital que permite aos professores coletar dados de avaliação formativa em tempo real sem a necessidade de dispositivos digitais para os estudantes. A ferramenta permite verificações rápidas de compreensão para que os professores possam saber se seus alunos estão compreendendo conceitos e dominando habilidades-chave.

\section{HORA DA REFLEXÃO...}

A importância da pesquisa para o estudo de gêneros e suporte está especialmente na essência em compreender como ou se os suportes formam e/ou transformam os gêneros textuais. Nesta perspectiva, as informações obtidas nos relatos nos permitiram compreender que há opiniões diferentes relacionadas ao suporte, mas quanto ao gênero, percebemos semelhanças nos relatos.

Apresentamos as discussões motivadas por duas perguntas, por meio das quais, os participantes expressaram suas percepções e experiências sobre a realização da prova objetiva em formato digital.

Das respostas apresentadas a partir da primeira pergunta - Como foi o processo de avaliação realizado em uma plataforma digital? - destacamos a ocorrência recorrente 
de algumas palavras, tais como "inovação", "interação", "era digital", "interessante" e "estranheza", considerando a escolha do instrumento, a ação da professora em sala de aula, o contexto atual e o sentimento dos participantes.

Alguns participantes relataram com a visão, de fato, de um futuro professor, percebendo o quão eficaz pode ser contar com a tecnologia em sala de aula, considerando o contexto atual da sociedade, e perceberam também o teor da elaboração das questões, bem como a organização do tempo para a resolução da prova, o que pode ser evidenciado na fala a seguir:

Foi uma excelente ação, muito interessante. Foram perguntas bem elaboradas, somente em algumas que eram mais complexas que necessitávamos de mais tempo para responder. As questões que tinham mais informações nas respostas precisava mais interpretação. É uma ferramenta muito prática, facilita para o professor, facilita para correção, aplicação e simultaneidade do desempenho do aluno também é um ponto positivo. (Su)

O fato de os alunos perceberem a relevância do aparato tecnológico pode ser considerado um ponto positivo, no entanto, para o foco da pesquisa, fica claro que o suporte digital interferiu na compreensão da proposta de avaliação, uma vez que alguns participantes ainda atribuíram caráter lúdico à avaliação. 
Em relação à segunda pergunta - A prova objetiva pode ser vista de outra maneira neste contexto? - buscamos compreender a percepção dos participantes com relação à maneira como pode ser vista a prova objetiva. Percebemos que para a maioria é diferente, pois muda a estrutura, pois "a prova não vem impressa". Alguns consideraram o momento da prova muito tenso, não considerando a ressignificação do suporte da prova. Para outros, foi um momento dinâmico e lúdico. Houve opiniões de que a prova objetiva não muda em nada, como expresso a seguir, no relato de um dos participantes.

O fato de ser uma avaliação ainda recai sobre a "prova" todas as validades, pressões e importâncias. O método da plataforma é mais divertido e diferente, requer ainda mais a atenção do aluno, pois não há chance de correção, o que aumenta ainda mais a pressão. Avaliação é avaliação em qualquer lugar e em qualquer método. (Hel)

Nesta perspectiva, o suporte não interferiu na compreensão do gênero trabalhado, "prova objetiva", diferente das opiniões que tratam a prova objetiva, na plataforma digital, como um jogo.

Considerando que a proposta da pesquisa foi analisar a percepção dos alunos acerca do suporte digital para a prova objetiva e verificar se o referido suporte interfere na 
definição e compreensão do gênero, constatamos que há, na maioria das vezes, certa dificuldade em compreender o gênero de acordo com o suporte que está sendo usado.

A cada situação comunicativa existe a possibilidade de novos gêneros serem criados, porém a mudança de um suporte para outro não pode transformar o gênero definitivamente. Fatores como a experiência, o contexto social do sujeito e a sua percepção interferem na definição e identificação dos gêneros.

Segundo os participantes desta pesquisa, o gênero prova objetiva em uma plataforma digital, é fluido, dinâmico, prático e inovador, interessante por desafiar a pensar rápido e não permitir correções nas respostas, porém, instiga o aluno a evoluir e preparar-se para acompanhar tempos modernos, podendo também ser entendida ou confundida como um jogo. Neste contexto, a prova é vista como uma simples atividade avaliativa, com objetivo de notas e aprovação, porém vai além e estimula outros sentidos, tais como: percepção, interpretação imediata, agilidade na resposta e segurança nas ações.

\section{CONSIDERAÇÕES FINAIS}

Para este estudo, foi necessário compreender os gêneros e seus suportes para delimitar sua pertinência na pesquisa 
e, desse modo, perceber as vantagens e desvantagens desta prática na formação de professores, bem como para compreender a sua relevância ao facilitar, complementar e implementar o ensino na formação de professores.

Durante a realização da pesquisa, foram trabalhadas várias habilidades a partir dos relatos mostrando a percepção dos participantes que consideraram a experiência como interessante, inovador, diferente, criativa, eficiente e desafiador, pois impulsiona a evolução e preparo para acompanhar tempos modernos na era digital.

Foi possível compreender que as inovações trazem prazer, estimulam e aprimoram o trabalho contínuo do professor em formação, facilita, motiva e transforma o ato de ensinar em algo prazeroso e o de aprender com a tecnologia e conhecimento, com maior fluidez e motivação. Neste caso, a partir da análise feita nos relatos dos participantes, consideramos que o gênero não muda somente porque muda/ressignifica o seu suporte. Identificar e compreender o gênero irá depender da percepção de cada interlocutor.

\section{REFERÊNCIAS}

ARAÚJO, Júlio César (2007). "Nicks \& emoticons no chat aberto: uma análise da ressignificação". In: CAVALCANTE, Mônica Magalhães et al. (Orgs.). Texto e discurso sob múltiplos olhares: gêneros e sequências textuais. Rio de Janeiro: Lucerna, p.38-61. 
BAKHTIN, Mikhail (2011). "Os gêneros do discurso". In: Estética da criação verbal. 6.ed. Paulo Bezerra (Trad.). São Paulo: Martins Fontes, p.261-306. ; VOLOCHÍNOV, Valentin N. (2006). Marxismo e Filosofia da Linguagem. 12.ed. Michel Lahud e Yara Frateschi Vieira (Trad.). São Paulo: Hucitec.

BEZERRA, Benedito Gomes (2007). "Do manuscrito ao livro impresso: investigando o suporte". In: CAVALCANTE, Mônica Magalhães et al. (Orgs.). Texto e discurso sob múltiplos olhares: gêneros e sequências textuais. Rio de Janeiro: Lucerna. p.9-37.

(2017). “Gêneros discursivos ou textuais?" In: BEZERRA, Benedito Gomes. Gêneros no contexto brasileiro. São Paulo: Parábola. p.17-31.

FREIRE, Maximina Maria (2017). “Uma abordagem metodológica e uma teoria do conhecimento: relato de um encontro e a emergência de uma tessitura". In: FREIRE, Maximina Maria; BRAUER, Karin Claudia Nin; AGUILAR Gabriel. (Orgs.). Vias para a pesquisa: reflexões e mediAÇÕES (e-book). São Paulo: Cruzeiro do Sul Educacional, Campus Virtual, v.1, p.173-180.

MARCUSCHI, Luiz Antônio (2002). "Gêneros textuais: definição e funcionalidade". In: DIONÍSIO, Ângela Paiva; MACHADO, Anna Rachel; BEZERRA, Maria Auxiliadora. (Orgs.). Gêneros textuais e ensino. Rio de Janeiro: Lucerna. p.19-36.

(2008). "Gêneros textuais no ensino de línguas". In: MARCUSCHI, Luiz Antônio. Produção textual, análise de gêneros e compreensão. São Paulo: Parábola. p.146-186.

ROJO, Roxane (2005). "Gêneros do discurso e gêneros textuais: questões teóricas e aplicadas". In: MEURER, José Luiz; BONINI, Adair.; MOTTAROTH, Desiree. (Orgs.) Gêneros: teorias, métodos, debates. São Paulo: Parábola. p.184-207.

Cristiane Ribeiro Magalhães é Mestranda em Estudos de Língua e Interculturalidade. UEG/POSLLI (Programa de Pós-graduação Stricto Sensu em Língua, Literatura e Interculturalidade). Grupo de Pesquisa 
Rede Cerrado de formação crítica de professoras/es de línguas, da Universidade Federal de Goiás.

E-mail: ribeirocristiane2611@gmail.com

Carla Conti de Freitas é Doutora em Politicas Públicas, Estratégia e Desenvolvimento, UFRJ/UEG, (2013) e Pós-Doutorado na Faculdade de Letras da Universidade do Porto. Atua como Docente e Diretora do Câmpus Inhumas da Universidade Estadual de Goiás e docente do Programa de Pós-graduação Stricto Sensu em Língua, Literatura e Interculturalidade. Grupo de Pesquisa Rede Cerrado de formação crítica de professoras/es de línguas, da Universidade Federal de Goiás.

E-mail: carlacontif@gmail.com 